\title{
Águas Subterrâneas Fluminenses e as Baixadas Metropolitanas: Panorama Atual e Perspectivas de Uso dos Recursos Naturais
}

\author{
Groundwater in Rio de Janeiro State and on \\ the Metropolitan Coastal Plains: Current Overview and \\ Perspectives for the Use of Natural Resources
}

\author{
Simone Lisboa Santos Silva \\ Universidade Federal do Rio de Janeiro \\ Rio de Janeiro, Brasil
}

\begin{abstract}
Resumo: O presente artigo se propõe a discutir a respeito das principais ameaças aos recursos hídricos nas baixadas fluminenses metropolitanas (aquelas que inserem-se na RMRJ - Região Metropolitana do Rio de Janeiro), que se referem aos terrenos de idade quaternária com morfologias planas e suaves, sendo por esta situação foco de interesse para ocupação. Aqui utilizamos como estudo de caso a atividade de extração de areia nas baixadas metropolitanas, pois estas representam um dos múltiplos usos que pode interferir diretamente na qualidade da água. Assim, ao se traçar um perfil desta atividade de mineração de areia podemos vislumbrar quais aquíferos apresentam-se mais vulneráveis no que diz respeito a esta atividade. Esta situação torna-se crítica devido à ausência de projetos de recuperção para as áreas onde a mineração seja desativada. Outro indicativo que reforça a correlação entre os recursos hídricos e o uso dos demais recursos naturais é o fato de que as alternativas de recuperação são baseadas exatamente na presença das lagoas formadas pela inundação das cavas. Finalmente, destacamos o caráter estratégico dos reservatórios de água subterrânea, os quais representam uma alternativa para um cenário crítico e emergencial (déficit no suprimento normal).
\end{abstract}

Palavras-chave: aquífero poroso, águas subterrâneas, baixadas, terrenos quaternários.

\begin{abstract}
This article treats the main threats to water resources in Quaternary terrain with level and gently inclined morphology located on the coastal plains of the Metropolitan Region of Rio de Janeiro. Due to favorable terrain conditions, the coastal plains are subject to multiple uses, of which sand extraction is analyzed here with regard to its influence on water quality and the most vulnerable aquifers are identified. The situation is made worse due to the absence of recovery projects after extraction ceases. The importance of water resources vis-à-vis other natural resources is seen in recuperation strategies based on the lakes formed by flooding of the excavated areas. Lastly, the strategic importance of groundwater reserves is highlighted as an alternative for an unfavorable scenario of deficit in normal water supply.
\end{abstract}

Keywords: porous aquifer, ground water, coastal plains, quaternary terrains. 
Silva, S. L. S.

\section{Apresentação e Objetivos}

As múltiplas abordagens que podem ser feitas a respeito da gestão de recursos hídricos traduzem não somente a complexidade do tema, como também a dificuldade de se compatibilizar interesses de atores tão diversos e divergentes, particularmente no que diz respeito ao uso, acesso e distribuição desses recursos. Neste tocante, e considerando a diversidade da configuração geomorfológica do Estado do Rio de Janeiro, fato gerador de grande variedade de ambientes, notamos que este possui um elevado potencial ambiental do ponto de vista paisagístico e de produção mineral. Ainda que a atividade mineral fluminense torne-se notável devido à produção de petróleo e gás realizada no Norte do estado, a qual ganha destaque pela relevância econômica e grande capital investido, temos ainda a exploração de fontes hidrominerais e agregados para construção civil (areia, pedra, brita) em diversas áreas do território.

No que se refere aos recursos hídricos, além dos recursos mais visíveis, como os corpos hídricos superficiais, canais e feições fluviais correlatas, não podemos deixar de considerar os recursos hídricos subterrâneos representados pelos aquíferos. Estes são reservatórios que devem ser encarados como reservas estratégicas de água, tanto para o cenário atual como para a proposição de cenários críticos e emergenciais. Desse modo, ao fazermos um breve levantamento da hidrogeologia fluminense, constatamos que, embora $80 \%$ das águas subterrâneas do estado correspondam a aquíferos fissurais devido a sua constituição geológica predominantemente cristalina, somente $20 \%$ correspondem aos aquíferos porosos localizados nas planícies fluviais e flúvio-marinhas. Estes últimos assumem grande importância quando analisados em termos de localização e formas de apropriação. Nesse sentido, cabe ressaltar a peculiaridade do ambiente no qual se desenvolve esse tipo de aquífero, cuja gênese está relacionada à própria formação dos terrenos de idade quaternária conhecidos como baixadas.

O presente artigo representa uma das etapas da pesquisa de dissertação da autora, que trata do estabelecimento de critérios e metodologias para identificação de potenciais áreas para atividade mineral e respectivas propostas de recuperação, utilizando especificamente como estudo de caso a exploração de depósitos arenosos na RMRJ. E ao longo desse processo de investigação, um aspecto que se destacou em termos de gestão e do próprio entendimento da dinâmica geomorfológica da área foi a questão da ocorrência concomitante desses depósitos arenosos explorados e dos aquíferos porosos. Na verdade, mais do que uma coincidência, há uma correlação muito forte entre o aquífero existente e a cobertura arenosa dos terrenos, já que a ocorrência de um é a própria condição de existência do outro. Isso nos leva a propor a discussão sobre a preservação da qualidade das águas subterrâneas fluminenses, no contexto das baixadas fluminenses metropolitanas, que são ambiente cujas formas de apropriação têm sido marcadas por usos exploratórios e intensivos. Nesse sentido, o artigo se propõe a traçar o panorama atual e as perspectivas de uso dos recursos naturais em ambientes de baixada, utilizando como caso de estudo a exploração de areia na RMRJ e constatando as tendências de expansão e/ou deslocamento espacial, para diante de tais constatações identificar quais aquíferos estariam mais suscetíveis às pressões da atividade. 


\section{Morfogênese dos Terrenos Quaternários e Associação com Aquíferos Porosos}

Devido a sua configuração morfológica (plana, suave, extensa), as baixadas fluminenses são foco de interesse tanto pelo favorecimento da ocupação humana quanto pela grande ocorrência de materiais úteis à cadeia produtiva. Em se tratando da evolução geomorfológica do Estado do Rio de Janeiro - nosso caso de interesse -, as baixadas fluminenses são bem representativas dos eventos deposicionais quaternários. Isto se deve ao fato de em suas depressões e nas bacias marginais serem encontrados depósitos correlativos aos ciclos erosivos e respectivas superfícies de erosão ${ }^{1}$ reconhecidos por Bigarella et al. (1975 apud AMADOR, 1997).

No caso brasileiro, essas regiões foram afetadas apenas indiretamente pelas glaciações, sofrendo alterações muito mais relacionadas às condições hidrológicas (regimes de chuvas e secas), do que aos eventos glaciais, submetendo-as a uma intensa alternância entre processos intempéricos químicos e físicos, originando morfologias eluviais e coluviais relacionadas ao desenvolvimento da drenagem. E nas áreas costeiras, a isso somou-se a influência das regressões e transgressões marinhas, resultando em interdigitações de depósitos fluviais, marinhos e flúvio-marinhos.

O termo "baixada" refere-se a uma "área deposicional proveniente de uma sedimentação fluvial, flúvio-marinha ou marinha, estando topograficamente deprimida em relação aos terrenos contíguos, ou junto à linha de costa" (ADAMY e DANTAS , 2004; p. 66). Tal situação topográfica e/ou locacional faz com que nessas áreas desenvolvam-se feições deposicionais com morfologias planas e suaves. Em consequência, esses locais se tornam foco de interesse tanto pelo favorecimento da ocupação humana como pela grande ocorrência de materiais úteis à cadeia produtiva. Esses materiais podem ser tanto recursos minerais como também recursos hídricos. Os recursos minerais são representados pelos depósitos arenosos, que constituem fonte de suprimento básico a variadas atividades produtivas, particularmente a indústria de construção civil. Os recursos hídricos são representados tanto pelas feições fluviais superficiais (canais, planícies e terraços) quanto pelas formações hidrogeológicas subsuperficiais (aquíferos), que coincidem com os terrenos quaternários por apresentarem uma correlação em suas gêneses, uma vez que o desenvolvimento dos aquíferos é possibilitado pela natureza permeável das camadas sedimentares desses terrenos.

Segundo o Instituto Geológico e Mineiro (2001), de acordo com a capacidade de armazenamento e transmissão de água, as formações geológicas podem ser classificadas em: 1) formações aquíferas, quando o reservatório de água subterrânea possui capacidade para armazenar e transmitir água, cuja exploração seja economicamente rentável; e 2) formações não aquíferas, quando seu aproveitamento não é rentável (seja pelas condições de armazenamento ou transmissão). Dito de outra maneira, os aquíferos são estruturas litoestratigráficas adequadas ao armazenamento e aproveitamento da água nelas contida, cujas origens podem estar associadas a: a) ocorrência de fissuras ou fraturas geológicas, que formam os chamados aquíferos fraturados e/ou fissurais; b) ocorrência de formações cársticas (calcário e dolomitos), nas quais o processo de dissolução forma reservatórios de água; e c) ocorrência de camadas sedimentares arenosas, cujas porosidade e permeabilidade (estruturação intersticial) são típicas das areias, facilitando 
a infiltração, circulação e armazenamento da água subterrânea. Resultam na formação dos chamados aquíferos porosos, cujas formações geológicas mais comuns são areias limpas, areias consolidadas por cimento (também denominadas arenitos), conglomerados etc.

Como o Estado do Rio de Janeiro apresenta constituição geológica predominantemente cristalina, as águas subterrâneas estão espacialmente mais distribuídas em aquíferos fissurais, uma vez que os aquíferos porosos localizam-se nas planícies litorâneas e bacias sedimentares, que cobrem apenas cerca de $20 \%$ do território fluminense. Embora os aquíferos porosos tenham menor extensão areal, desempenham papel relevante para as localidades em que se encontram, devido principalmente a sua alta produtividade e localização próxima aos conglomerados urbanos. Os sistemas aquíferos porosos fluminenses referem-se aos aquíferos terciários, com espessura estimada de 10 a 30 metros; ao aquífero Macacu, com espessuras variáveis de 30 até 200 metros; e aos aquíferos flúvio-lacustres, associados aos aluviões de rios, entre os quais se destacam os aluviões associados aos rios Macacu, Guandu e Macaé, que podem atingir até 100 metros de espessura (MARTINS et al., 2008).

Notamos a existência dessa correlação entre os depósitos arenosos e os aquíferos quaternários na própria Baixada Fluminense, que pode ser segmentada em: baixada de Campos dos Goitacazes, baixada de Arauama, baixada de Guanabara, baixada de Sepetiba e baixada de Jacarepaguá. Estas, por sua vez, estão associadas aos respectivos sistemas aquíferos. As baixadas da Guanabara, Sepetiba e Jacarepaguá despertam peculiar interesse, pois compreendem os municípios integrantes da RMRJ (Figura 1) e, portanto, desempenham papel estratégico.

Consideramos que as baixadas ditas metropolitanas apresentam uma particularidade frente às demais baixadas fluminenses, justificada por sua localização estratégica - requisito primordial para o abastecimento de materiais volumosos e com baixo valor agregado - e por estarem inseridas numa rede logística que lhes oferece ainda mais possibilidades de escoamento da produção. Diante desses aspectos, no presente estudo consideramos as baixadas de Jacarepaguá, baía de Guanabara e baía de Sepetiba como baixadas metropolitanas, uma vez que compreendem os municípios integrantes da RMRJ e vêm sofrendo uma crescente pressão decorrente da expansão urbana ou da prática de atividades exploratórias desordenadas. Embora tal situação não seja exclusiva ao território fluminense, este desempenha um papel bem representativo a respeito de questões e conflitos ambientais comuns aos grandes centros urbanos brasileiros. Questões estas representadas por conflitos de interesses e poderes envolvendo a distribuição e uso (desiguais) dos recursos ambientais. E ainda que a apropriação desses recursos pela sociedade se faça de variadas formas, a mais tradicional e emblemática delas é a exploração mineral. Trata-se de uma atividade em que os aspectos negativos são mais visíveis e pronunciados, devido ao caráter extrativo e intensivo, dada a retirada e mobilização de grandes volumes de materiais e consequente interferência significativa na dinâmica dos ambientes. Entretanto, do ponto de vista estratégico, a exploração mineral faz-se necessária como fonte supridora de grande parte dos insumos da cadeia produtiva. 


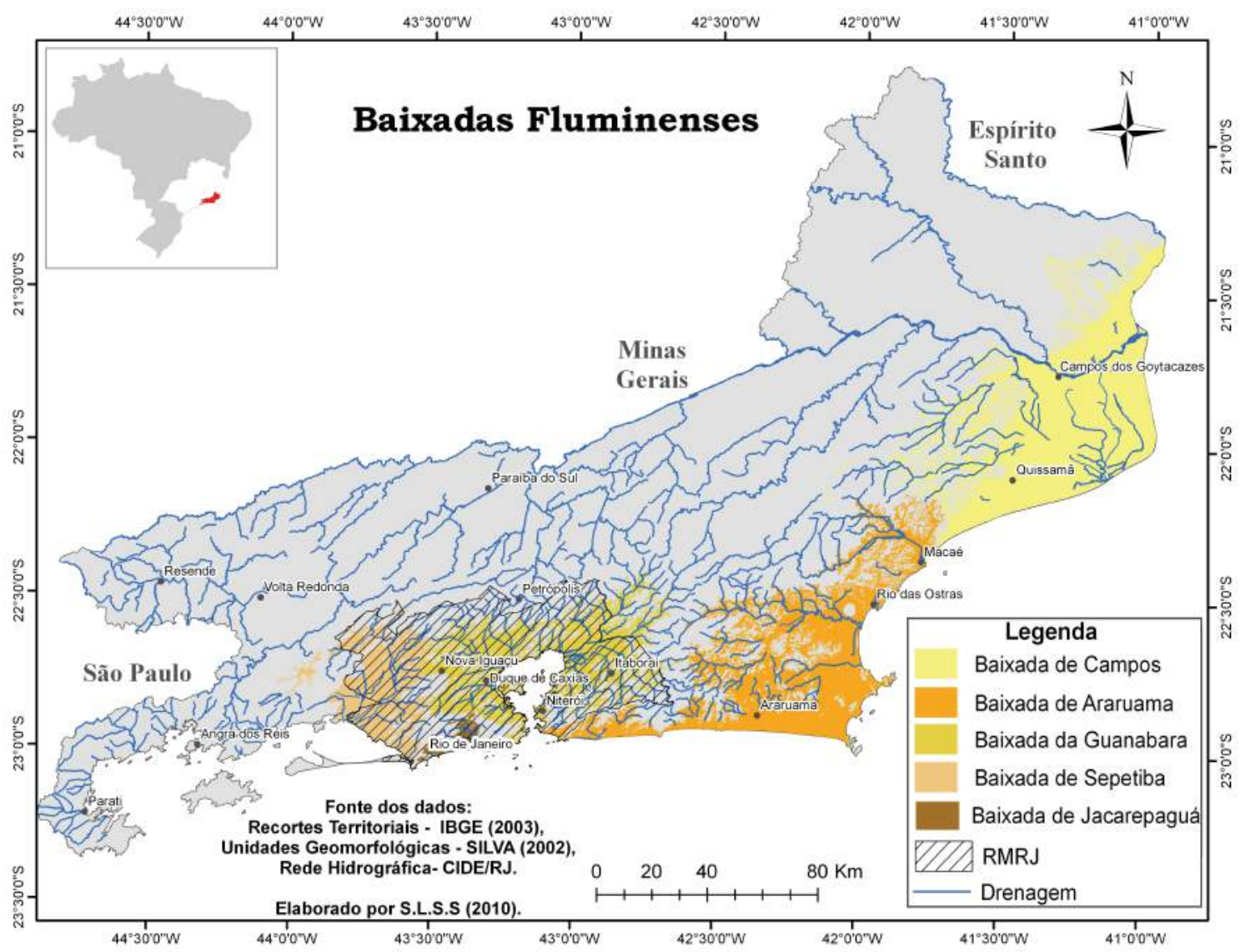

Figura 1 - Baixadas da costa fluminense - Fonte dos dados geomorfológicos: Silva (2002). Elaborado por Silva 2010.

No que diz respeito à atividade mineral fluminense, como já indicado, além da produção de petróleo e gás, temos ainda a exploração de fontes hidrominerais e agregados para construção civil (areia, pedra, brita) em ambientes de baixadas e feições fluviais. Ainda que inicialmente não se perceba toda a relevância econômica associada a essa atividade, posto que se refere à produção de um material de baixo valor agregado e de relativa abundância, uma análise um pouco mais apurada revela sua articulação a diversos setores econômicos. Segundo Cooke e Doornkamp (1990), areia e cascalho², ambos materiais básicos utilizados na construção civil, representam, em termos de tonelagem, os dois recursos minerais mais relevantes ao nível mundial. Em se tratando da produção brasileira, de acordo com o Departamento Nacional de Produção Mineral (DNPM) (2008), nos últimos anos, o país vem seguindo esta tendência mundial e aumentando sua produção. O Estado do Rio de Janeiro figura como segundo maior produtor nacional, abaixo somente do Estado de São Paulo.

Essa atividade mineral, por seu próprio caráter exploratório aliado à falta de planejamento, que nesse caso tem sido usual, resulta em impactos ambientais de grandes proporções tendo em vista o volume de material extraído e remobilizado. Genericamente, os impactos associados referem-se às lagoas formadas pela contínua escavação que atinge o lençol freático, com subsequente abandono das lagoas após tornarem-se improdutivas para mineração. Há também a formação de lagoa de rejeitos com os sedimentos finos que restam após a seleção feita através da lavagem do material útil. 
Portanto, o cenário que se desenha é o de lagoas (cavas) em progressão, alastrando-se na vertical e sobretudo na horizontal, adjacentes a aterros artificiais com camadas de sedimentos homogeneamente finos (lagoas de rejeitos) e bem selecionados pela lavagem. Destas condições decorrem as maiores preocupações a respeito dos danos que a mineração pode causar aos recursos hídricos, pois as áreas de extração coincidem com os terrenos correspondentes às camadas de sedimentos porosos que propiciam a origem, proteção e manutenção dos aquíferos.

O cenário delineado já pode ser constatado na atual área supridora de areia da RMRJ, a bacia hidrográfica do rio Guandu, pertencente à bacia da baía de Sepetiba, apresentando em suas planícies fluviais e/ou flúvio-marinhas depósitos com espessuras consideráveis que giram em torno de 20 metros. A delimitação institucional dessa bacia, segundo o decreto $\mathrm{n}^{\circ} 31.178 / 2002-\mathrm{RJ}$, que cria seu respectivo comitê, é definida como:

Bacia Hidrográfica do Rio Guandu, incluídas as nascentes do Ribeirão das Lages, as águas desviadas do Paraíba do Sul e do Piraí, os afluentes ao Ribeirão das Lages, ao rio Guandu e ao canal de São Francisco, até a sua desembocadura na Baía de Sepetiba, bem como as Bacias Hidrográficas do rio da Guarda e Guandu-Mirim.

A região da bacia do rio Guandu se destaca por ter protagonizado, desde o início de sua ocupação no início do século XVII, inúmeras intervenções que alteraram sobremaneira sua configuração natural, particularmente seus sistemas de drenagens, através de retificações dos canais.

Considerando que a exploração dos depósitos arenosos concentra-se na zona Oeste da bacia do Guandu, coincidindo com a extensão do aquífero poroso Piranema (Figura 2), a atual situação ambiental da bacia do Guandu tem se caracterizado pela deflagração de diversos conflitos a respeito das divergentes demandas de uso do solo, recursos hídricos e minerais. Ressaltando o papel desempenhado pelo seu comitê, este tem como atribuição promover a articulação entre os diferentes agentes envolvidos, arbitrando conflitos, aprovando e acompanhando o Plano de Recursos Hídricos da bacia - documento de apoio técnico e gerencial às decisões disponível na Fundação Superintendência Estadual de Rios e Lagoas - SERLA (www.serla.gov.br). No caso do Plano Estratégico de Recursos Hídricos da Bacia do Guandu, as ações prioritárias consistem na ordenação do uso do solo, de acordo com os seguintes princípios: gerenciamento integrado dos recursos, recuperação da qualidade ambiental e garantia da qualidade e quantidade dos recursos hídricos (IPT, 1992; SONDOTÉCNICA, 2005).

De acordo com Marques (2005), o sistema aquífero Piranema refere-se à formação sedimentar, composta por sedimentos arenosos e areno-argilosos com permeabilidade intergranular, apresentando extensão de aproximadamente $180 \mathrm{~km}^{2}$, cuja zona de recarga é a própria superfície do terreno. Tendo $0,5<\mathrm{q}<3\left(\mathrm{~m}^{3} / \mathrm{h} / \mathrm{m}\right)$ de vazão específica, é classificado como aquífero do tipo poroso e livre, com qualidade da água considerada boa a levemente ferruginosa. Esse fato propicia seu uso para o abastecimento da população local, no bairro Piranema (Itaguaí), através de poços artesianos e cacimbas. Portanto, alterações no lençol freático que modifiquem a qualidade ou a disponibilidade de suas águas causariam efeitos diretos no abastecimento local, além da possível alteração da dinâmica hidrogeológica regional, visto que a mineração, ao atingir o lençol, provoca seu rebaixamento e o expõe aos agentes de contaminação (BERBET, 2003; MARQUES, 2005; MARTINS et al., 2008). 


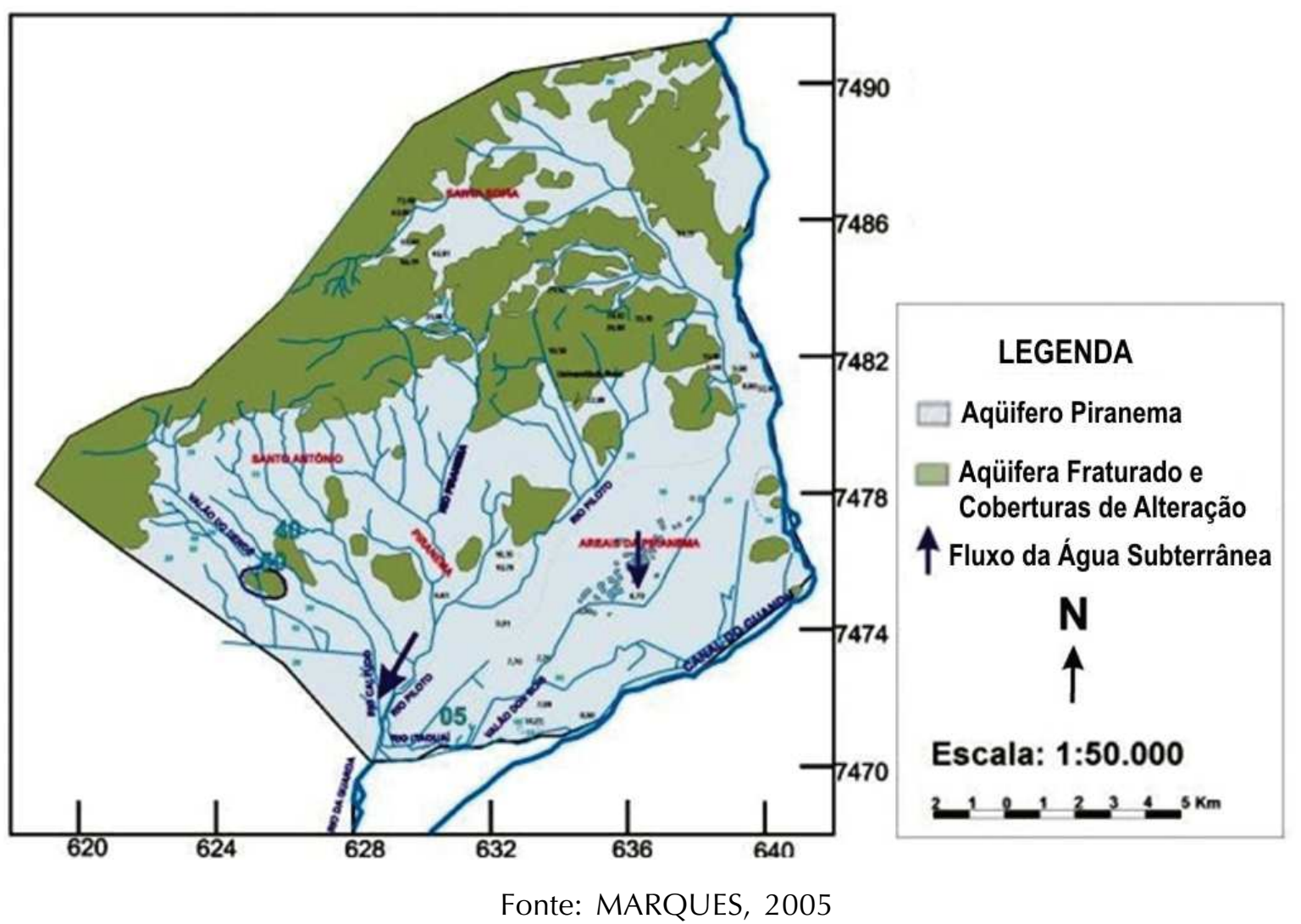

Figura 2 - Área de ocorrência do aquífero Piranema na bacia do rio Guandu.

Dentre estas preocupações sobre as ameaças ambientais aos recursos hídricos, emerge a discussão sobre o grau de ameaça que tais práticas impõem aos aquíferos. Para tanto, recorremos ao esclarecimento sobre dois termos complementares: o de "risco", que envolve situação de perigo ou dano, em razão da possibilidade de ocorrência de um processo induzido ou não (ZUQUETTE e GANDOLFI, 2004); e o de "vulnerabilidade" que, segundo Auge (2004), deve ser entendido a partir de duas perspetivas - a de vulnerabilidade intrínseca e a de vulnerabilidade específica. A primeira está associada às próprias características do aquífero, como natureza litológica, grau de porosidade e permeabilidade que determinam como ele reagirá a uma ação negativa, seja natural ou antrópica, estando relacionada a sua capacidade de absorver alterações adversas. Já a segunda perspectiva refere-se à conjugação da vulnerabilidade intrínseca com a existência de risco associado a um evento específico, como por exemplo a vulnerabilidade (específica) à contaminação ou à alteração do fluxo de recarga.

Tendo em vista a resolução no 396/2009 do Conselho Nacional do Meio Ambiente (CONAMA), as águas subterrâneas por definição ocorrem natural ou artificialmente no subsolo, tendo como principal característica o fato de estarem protegidas por camada de determinado material, sendo solo, rocha ou suas alterações. E devido a essa relativa proteção, que varia de acordo com vulnerabilidade intrínseca do aquífero, estão menos propensas à contaminação do que as águas superficiais. Por isso, os aquíferos são considerados excelentes reservatórios estratégicos de água. Em contrapartida, quando as águas subterrâneas são contaminadas, o processo utilizado para descontaminá-las é difícil e oneroso, tornando medidas preventivas de preservação dos aquíferos uma necessidade imediata (em termos qualitativos e quantitativos). 
Silva, S. L. S.

\section{Estrutura Metodológica}

Metodologicamente, o estudo estruturou-se a partir da análise conjugada de dados referentes a: a) mapeamento geomorfológico realizado por Silva (2002); b) localização e distribuição espacial, extensão do areal e informações cadastrais a respeito da exploração de areia, disponibilizadas no site do DNPM; c) recortes territoriais fornecidos no site do Instituto Brasileiro de Geografia e Estatística (IBGE); e d) bases sobre o sistema viário e uso do solo, fornecidos pelo Grupo ESPAÇO/UFRJ, coordenado pela profa. Carla Madureira.

O mapeamento geomorfológico foi considerado plano de informação primário, pois com a identificação das áreas de acúmulo de sedimentação quaternária e a partir da interpretação da morfologia (planícies fluviais e flúvio-marinhas), é possível inferir sobre seu potencial para ocorrência de depósitos arenosos. A base utilizada refere-se aos mapas geomorfológicos produzidos por Silva (2002) em escala de semidetalhe (1:50.000), utilizando a técnica de cálculo da amplitude altimétrica $(\Delta \mathrm{h})$ proposta por Meis et al. (1982). Essa metodologia consiste em calcular Dh, que é dada pela diferença entre as altitudes superior $\left(\Delta h_{\text {máx. }}\right)$ e inferior $\left(\Delta h_{\text {mín. }}\right)$ de bacias de drenagem de primeira e segunda ordem até sua confluência com a rede coletora, utilizando-se cartas topográficas. Os autores definem a bacia de drenagem como unidade básica de reconhecimento das diferentes classes de amplitude altimétrica, tendo em vista seu significado fundamental para compreensão das relações entre área-fonte, zona de transporte e zona de deposição em ambientes geodinâmicos distintos. O produto cartográfico final apresentado por Silva (2002) foram cartas morfoestruturais confeccionadas em AutoCAD, que são arquivos de extensão .dwg. Estes foram posteriormente convertidos em arquivos .shp para poderem ser tratados no ambiente de Sistema de Informações Geográficas (SIG), que neste trabalho se refere ao software ArcGIS 9.2.

Para obtenção dos dados espaciais e cadastrais sobre a produção de areia fluminense, recorreu-se à ferramenta Sistema de Informações Geográficas da Mineração (SIGMINE) (http://sigmine.dnpm.gov.br/), disponibilizada pelo DNPM. Foram obtidos os dados referentes ao arquivo .shp (representação espacial) e tabela associada contendo informações sobre a área do empreendimento, ano do cadastro, responsável e fase na qual se encontra o empreendimento: requerimento de pesquisa, autorização de pesquisa, requerimento de licenciamento, licenciamento, requerimento de lavra e disponibilidade.

No que se refere ao uso do solo, dentre as diversas classes elencadas pela base de dados fornecida pelo Grupo ESPAÇO/UFRJ, consideramos como indicador de expansão urbana a classe intitulada "áreas urbanas". E quanto ao sistema viário, este serviu de indicador de inserção na rede logística da RMRJ. Complementando as análises, foram ainda utilizadas informações da Secretaria de Obras do Estado do Rio de Janeiro para delimitar manualmente o traçado previsto para o futuro arco viário metropolitano. Essa etapa de tratamento dos dados secundários em ambiente SIG (ArcGIS 9.2) utilizou ferramentas de sobreposição de recortes espaciais, consultas e cálculos geométricos, resultando em mapas e tabelas, indicando áreas propícias a análises mais refinadas, ou seja, áreas apresentando indícios de que a atividade mineral avança e se instala sobre reservas de água subterrânea.

As análises basearam-se também em levantamento bibliográfico a respeito das tendências de expansão urbana, tendo em vista que esse processo é o principal vetor 
a fomentar o mercado da construção civil e, portanto, acaba por se tornar um dos fatores impulsionadores da produção de areia. Sendo assim, as investigações de Becker e Paganoto (2008), sobre os ritmos de crescimento populacional (considerando a população residente) da RMRJ para o período de 1980 a 2000, auxiliam na compreensão do panorama regional. Os autores classificam os municípios pertencentes a RMRJ em três grupos, a saber: 1) os que apresentam diminuição do ritmo de crescimento populacional, no qual se enquadram os municípios de Nilópolis, Niterói, Paracambi, Tanguá, São Gonçalo e Belford Roxo; 2) os que apresentam estabilidade ou pequeno crescimento populacional, que englobam os municípios de São João de Meriti, Rio de Janeiro, Duque de Caxias e Nova Iguaçu; e 3) aqueles com elevação do ritmo de crescimento ou manutenção de altas taxas de crescimento, incluindo Guapimirim, Seropédica, Japeri, Queimados, Magé e Itaboraí. Particularmente, na classe de municípios que apresentam crescimento populacional, nota-se uma tendência à expansão da população da RMRJ em todas as direções: ao leste, com Itaboraí; ao norte-nordeste, com Guapimirim e Magé; e para o oeste, com Seropédica, Japeri e Queimados. Corroborando estas proposições, Egler et al. (2003), em sua proposta de zoneamento ambiental da baía de Guanabara, apontam que embora a urbanização esteja concentrada nas orlas ocidental (Rio de Janeiro e Duque de Caxias) e oriental (Niterói, São Gonçalo e Itaboraí), os vetores considerados mostram orla setentrional (Magé e Guapimirim) como novo foco de expansão.

\section{Resultados e Discussões}

Nestas análises, o primeiro aspecto que se destaca é o fato de grande parte das feições quaternárias identificadas coincidir com as áreas de ocupação e expansão urbana (Figura 3). Fato já esperado, tendo em vista que tais terrenos associam-se às formas planas e suaves, facilitadoras da ocupação e construção. Assim, embora teoricamente o recurso mineral areia seja abundante na superfície terrestre, os locais de seus depósitos já apresentam outros usos que impedem sua exploração. Dessa maneira, um fator preponderante nas análises de áreas propícias a tal atividade é o requerimento de apresentar uma fraca ocupação urbana, e ainda assim estarem inseridas numa rede de infraestrutura que facilite o escoamento da produção sem encarecimento do produto. Portanto, é recomendado certo grau de afastamento do núcleo central, pois essas áreas apresentam usos de solo mais densos e restritivos. Entretanto, exige-se que tal afastamento respeite os limites impostos pelos custos de transporte.

Tais análises, embasadas pelo levantamento bibliográfico teórico-conceitual, permitiram delinear as tendências atuais de expansão da atividade exploratória rumo às planícies da porção setentrional da baixada da baía de Guanabara, correspondente aos municípios de Magé e Guapimirim. Não por acaso, essa expansão coincidiu com o sentido da expansão intraurbana metropolitana já indicada por Egler et al. (2003) e Becker e Paganoto (2008). Diante dessas perspectivas, o questionamento pertinente diz respeito à maneira como são tratados os dilemas ambientais já enfrentados nas áreas de exploração consolidadas, a exemplo do que ocorre na bacia do Guandu, com relação à vulnerabilidade do aquífero Piranema (MARTINS, 2008). 


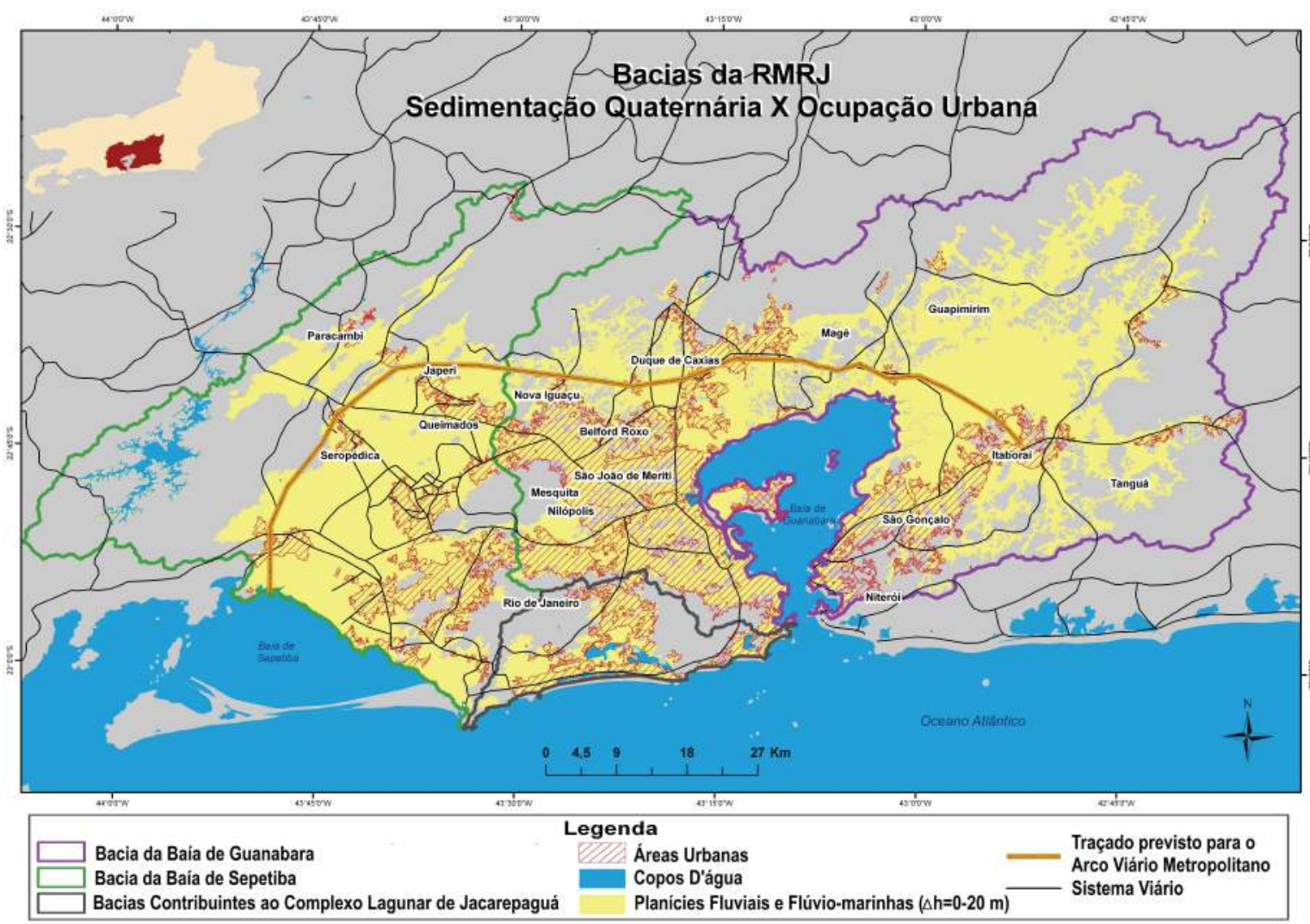

Figura 3 - Distribuição da sedimentação quaternária correspondente aos depósitos arenosos das baixadas metropolitanas e representação das áreas urbanas (elaborado por SILVA 2010).

Em termos de área, a baixada da Guanabara se destaca por apresentar cerca de 4.041 $\mathrm{km}^{2}$ de extensão, seguida pela baixada de Sepetiba que possui $2.295 \mathrm{~km}^{2}$, enquanto a baixada de Jacarepaguá apresenta uma área de apenas $325 \mathrm{~km}^{2}$. Assim, por sua pouca expressão areal em comparação as duas primeiras e também pelo fator de constrangimento relacionado a sua localização (completamente inserida no município do Rio de Janeiro, sendo alvo de forte pressão urbana e especulação imobiliária, visto que corresponde a um corredor de expansão de ocupação relacionado aos bairros emergentes da zona Oeste [Barra, Recreio, Jacarepaguá]), considera-se que a baixada de Jacarepaguá apresenta já outros usos predominantes que inibem a presença de atividade mineral. Sendo assim, as análises seguintes tomam por base somente as baixadas de Sepetiba e da Guanabara.

Ao atentarmos para a base cadastral do DNPM/SIGMINE, referente à exploração de areia no Rio de Janeiro, notamos que ambas as baixadas já demonstram a presença desse setor em suas áreas. Entretanto, sutis diferenças são apontadas nas dimensões dos estabelecimentos mineradores, assim como na fase de operação em que se encontram. Diante disso, algumas tendências foram observadas: 1) embora a baixada da Guanabara apresente um número total de empreendimentos cadastrados bem menor do que a baixada de Sepetiba (Tabela 1), a partir do ano 2000 apresentou um ritmo de crescimento do número de empreendimentos cadastrados similar ao daquela, chegando inclusive a ultrapassá-la a partir do ano de 2007 (Tabela 2). Tal fato pode ser 
relacionado a um maior rigor da legislação ambiental - com intensificação das pressões para um controle mais efetivo - e ao reaquecimento do mercado da construção civil impulsionado pelos grandes empreendimentos, como o arco rodoviário metropolitano, a instalação do Complexo Petroquímico do Rio de Janeiro (COMPERJ), entre outros. 2) As baixadas de Sepetiba e da Guanabara diferenciam-se também pelas proporções de tamanho, com a maioria dos areais da baixada de Sepetiba (Figura 4) apresentando áreas menores e sendo inferidos como mais profundos, devido ao tempo de exploração; 3 ) encontram-se mais concentrados espacialmente do que na baixada da Guanabara (Figura 5).

Tabela 1 - Quantidade de empreendimentos de exploração de areia cadastrados por década até o ano de 2000.

\begin{tabular}{lcc}
\hline Ano & Baixad a de Sepetiba & B aixad a da G uanabara \\
\hline $\mathbf{1 9 7 0}$ & 3 & 1 \\
$\mathbf{1 9 8 0}$ & 2 & 0 \\
$\mathbf{1 9 9 0}$ & 31 & 7 \\
$\mathbf{2 0 0 0}$ & 146 & 139 \\
\hline Total & 182 & 147 \\
\hline
\end{tabular}

Fonte dos dados: SIGMINE - DNPM / 2009.

Tabela 2 - Quantidade de empreendimentos de exploração de areia cadastrados por ano após 2000.

\begin{tabular}{lcc}
\hline Ano & Baixada de Sepetiba & Baixada da Guanabara \\
\hline 2001 & 4 & 5 \\
2003 & 10 & 1 \\
2005 & 5 & 11 \\
2007 & 28 & 30 \\
2009 & & 13 \\
\hline
\end{tabular}

Fonte dos dados: SIGMINE - DNPM / 2009. 


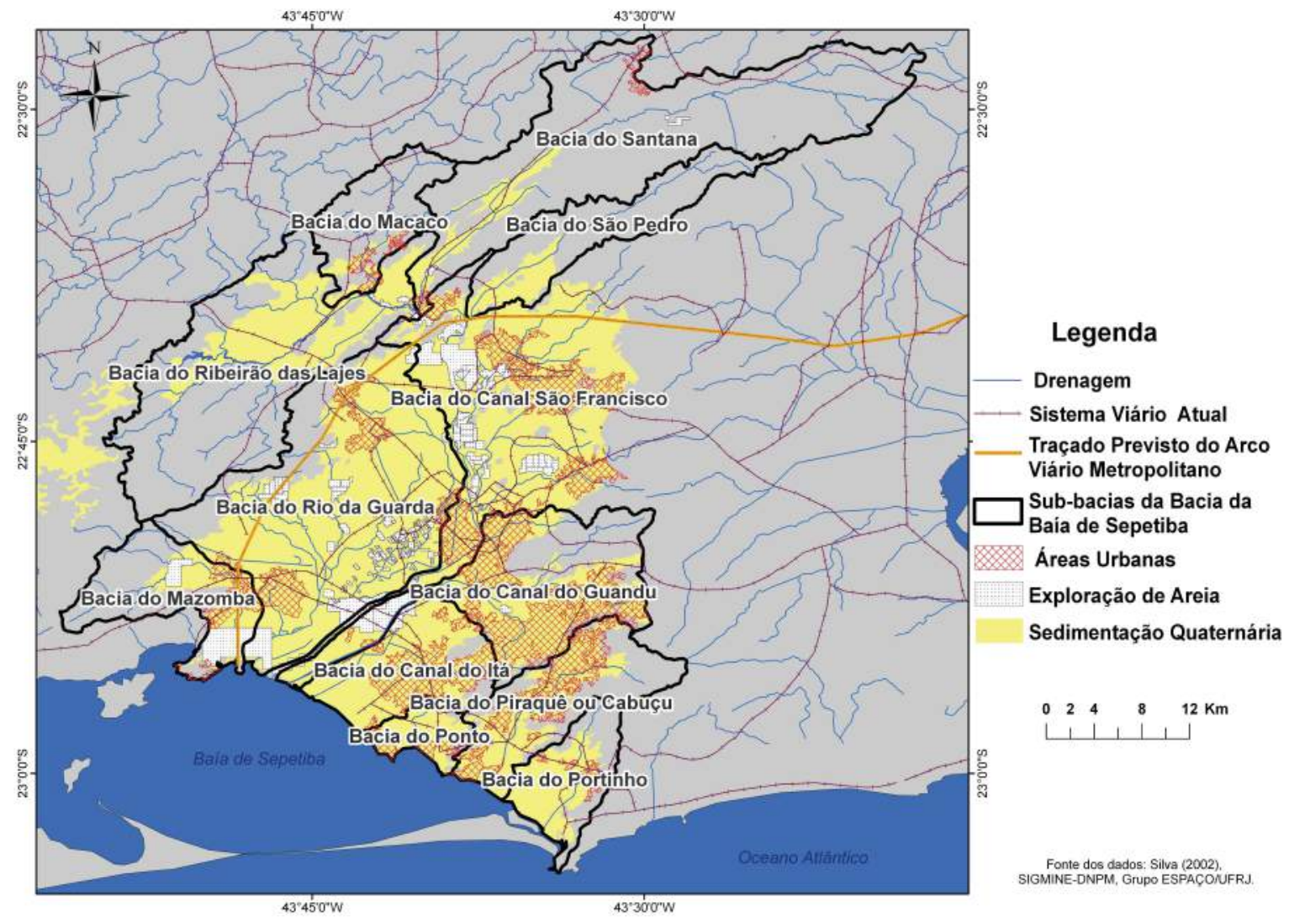

Figura 4 - Bacia do rio Guandu e sub-bacias hidrográficas, com localização dos depósitos quaternários correspondentes ao domínio morfológico da baixada de Sepetiba. Estão representadas também as áreas urbanas e a localização das áreas de exploração mineral (Elaborado por SILVA 2010).

A baixada de Sepetiba, por representar a tradicional área supridora de areia para RMRJ, já apresenta um quadro deflagrado de degradação ambiental relacionado à mineração e seus impactos. Esse quadro de degradação está associado às modificações morfológicas acarretadas pela abertura de cavas de grandes proporções, que atingem o lençol freático, fazendo-o aflorar e deixando-o mais suscetível em termos de contaminação e alterações da dinâmica hidrológica. Tal fato faz com que a vulnerabilidade intrínseca do aquífero local - o aquífero de Piranema - seja potencializada pelos riscos decorrentes da remoção da camada porosa de sedimentos, acarretando alterações na dinâmica hidrogeológica (nos processos de infiltração, transmissão e evaporação). 


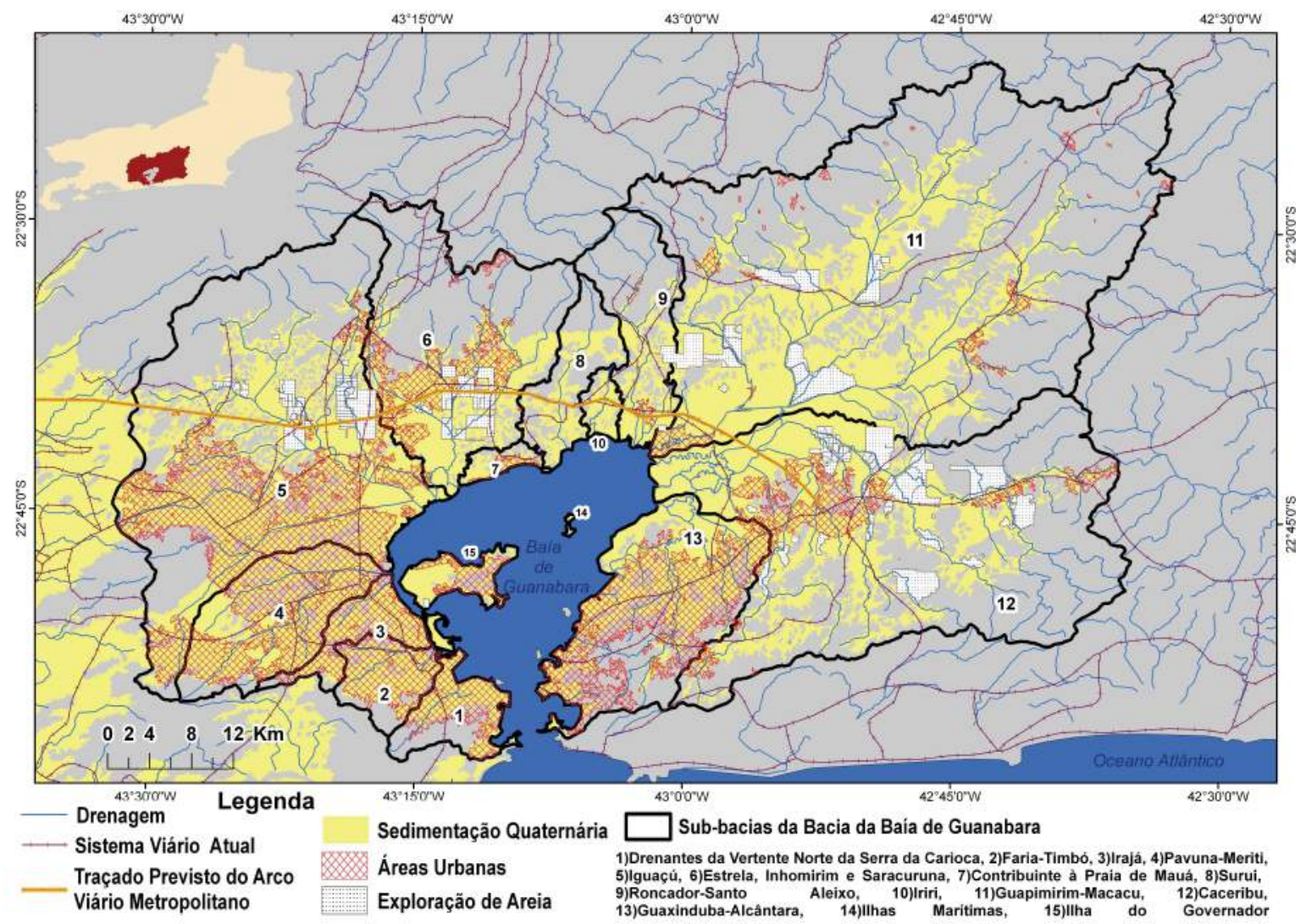

Figura 5 - Bacias da Guanabara e Guandu com respectivas sub-bacias hidrográficas e localização dos depósitos quaternários correspondentes ao domínio morfológico da baixada da Guanabara. Estão representados também as áreas urbanas e a localização das áreas de exploração mineral (Elaborado por SILVA 2010).

Já na baixada da Guanabara (Figura 5), onde a atividade está se expandindo em direção à porção setentrional (Magé e Guapimirim), mais especificamente em relação às bacias de Roncador-Santo Aleixo, bacia do Iriri e bacia de Guapimirim-Macacu, há que se ponderar sobre os riscos impostos aos aluviões e aquíferos correspondentes. O que merece maior destaque é o aquífero Macacu, localizado na parte sul da bacia hidrográfica do rio Macacu, que se estende por aproximadamente $110 \mathrm{~km}^{2}$.

\section{Alguns Apontamentos e Diretrizes Finais}

Diante do exposto, o que se argumenta é que a gestão não deve versar unicamente sobre uma determinada categoria de recurso (mineral ou hídrico), mas sim se fundamentar em uma concepção integrada que trate da gestão de um ambiente peculiar, como é o caso das baixadas, onde há concentração natural desses recursos. Por fim, ressaltamos que, se o cenário atual já indica a existência de uma maior pressão nos aquíferos porosos associados aos aluviões dos rios Macacu e Guapiaçu, qualquer prognóstico em relação aos recursos hídricos dessa região deverá salientar o caráter vulnerável desses reservatórios frente ao tipo de uso exploratório a avançar sobre os aquíferos locais.

A situação torna-se ainda mais crítica devido à falta de um projeto de recuperação ambiental dessas cavas quando sua exploração for desativada. Nesse tocante, outro 
Silva, S. L. S.

indicativo reforçador da correlação existente entre a gestão de recursos hídricos e o uso dos demais recursos minerais é o fato de as alternativas de recuperação para os terrenos com mineração de areia desativada (p. ex., piscicultura, implantação de áreas de lazer para práticas de pesca, passeios de barcos etc.) basearem-se justamente na presença de lagoas formadas pela inundação das cavas.

Por fim, ressalta-se mais uma vez o caráter estratégico dos reservatórios de água subterrânea, sobretudo quando se considera os serviços públicos em geral prestados à população da baixada Fluminense - reconhecidamente deficientes. De tal modo, torna-se necessário projetar cenários futuros, desde situações favoráveis (ampla disponibilidade e distribuição de água) até panoramas críticos e emergenciais (déficits no abastecimento), nos quais os aquíferos metropolitanos (locais) desempenham papel estratégico.

\section{Agradecimentos}

A autora agradece à professora Telma Mendes (Departamento de Geografia, UFRJ), que tem orientado e colaborado muitíssimo para realização não somente deste artigo como dos demais trabalhos relacionados ao meu projeto de dissertação. Agradecimentos também ao Grupo ESPAÇO-UFRJ, coordenado pela profa. Carla Madureira, pela gentileza em ceder sua bases de dados de uso do solo.

\section{Referências Bibliográficas}

AUGE, M. Vulnerabilidad de acuíferos. Revista Latino-Americana de Hidrogeologia, n4, p. 85-103, 2004. Disponível em: http://ojs.c3sl.ufpr.br/ojs2/index.php/hidrogeologia/ article/view/2652/2193. Acesso realizado em 30 de setembro de 2009.

ADAMY, A . e DANTAS, M. E. Geomorfologia - Setor Jirau. Porto Velho: Convênio FURNAS/ CPRM, 2004.

AMADOR, E. S. Baía de Guanabara e Ecossistemas Periféricos: Homem e Natureza. Rio de Janeiro: E.S. Amador, 1997.

BERBET, M. C. A mineração de areia no distrito areeiro de Itaguaí-Seropédica/RJ: Geologia dos depósitos e caracterização das atividades de lavra e dos impactos ambientais. Tese de Doutorado. Programa de Pós-Graduação em Geologia, 2003, Universidade Federal do Rio de Janeiro.

BECKER, O . M. S., PAGANOTO, F. A População Migrante na Região Metropolitana do Rio de Janeiro: uma abordagem espacial das desigualdades em 2000. In: Anais do XVI Encontro Nacional de Estudos Populacionais. Caxambu-MG: ABEP, 2008.

CONAMA - CONSELHO NACIONAL DO MEIO AMBIENTE. Resolução n 396, de 03 de abril de 2008. Dispõe sobre a classificação e diretrizes ambientais para o enquadramenro das águas subterrâneas e dá outras providências. Disponível em <http:// 
www.mma.gov.br/port/conama/legiabre.cfm?codlegi=562>. Acesso realizado em 8 de novembro de 2009.

COOKE, R. U.; DOORNKAMP, J. C. Geomorphology in environmental management: a new introduction. 2 edition. Oxford: Clarendon Press, 1990.

DNPM - Departamento Nacional de Produção Mineral. Sumário Mineral 2008 - Agregados para Construção Civil. DNPM, 2008. Disponível em: www.dnpm.gov.br. Acesso realizado em 27 de abril de 2009.

EGLER, C. A. G.; CRUZ, C. B. M.; MADSEN, P. F. H.; COSTA, S. M.; SILVA, E. A. Proposta de Zoneamento Ambiental da Baía de Guanabara. Anuário do Inst. Geociências/UFRJ, Rio de Janeiro, v. 26. 2003. p. 127-138.

IBGE - Instituto Brasileiro de Geografia e Estatística. Disponível em www.ibge.gov.br/ mapas_ibge/bases.php. Acesso realizado em 10 de dezembro de 2008.

INSTITUTO GEOLÓGICO E MINEIRO (2001). Água Subterrânea: Conhecer para Preservar o Futuro. Instituto Geológico e Mineiro. Disponível em: http://e-Geo.ineti.pt/ geociencias/ edicoes_online/diversos/agua_subterranea/indice.htm. Acesso realizado em 29 de setembro de 2009.

IPT - INSTITUTO DE PESQUISAS TECNOLÓGICAS. $3^{\circ}$ Curso de Geologia de Engenharia Aplicada a Problemas Ambientais. São Paulo: ABAMA/DIGEM, 1992. (Apostila Mimeografada).

MARTINS, A. M. ; CAPUCCI, E. ; CAETANO, L. C. ; CARDOSO, G.; BARRETO, A. B. C.,.MONSORES, A. L. M., LEAL, A. S ; VIANA, P. Hidrogeologia do Estado do Rio de Janeiro- Síntese do estágio atual do conhecimento. In: XIV Congresso Brasileiro de Águas Subterrâneas: ABAS, 2008. p.1-17.

MARQUES, E. D. Hidrogeoquímica nas cavas de extração de areia na região do Bairro de Piranema - Distrito Areeiro de Seropédica - Itaguaí - RJ. Dissertação de Mestrado. Niterói:UFF, 2005.

MEIS,M.R.; MIRANDA,L.H.G. e FERNANDES,N.F. Desnivelamento de altitude como parâmetro para a compartimentação do relevo: bacia do médio-baixo Paraíba do Sul. In Congresso Brasileiro de Geologia, 32, 1982, Salvador . Anais... Salvador: SBG. 4:1489-1509.

SERLA - Fundação Superintendência Estadual de Rios e Lagoas. Disponível em www.serla.gov.br. Acesso realizado em 26 de março de 2009. 
Silva, S. L. S.

SIGMINE - Informações Geográficas da Mineração do DNPM - Departamento Nacional de Produção Mineral. Disponível em http://sigmine.dnpm.gov.br/. Acesso realizado em 27 de abril de 2009.

SILVA, T. M. A Estruturação Geomorfológica do Planalto Atlântico no Estado do Rio de Janeiro. Tese Doutorado. Rio de Janeiro: UFRJ, 2002.

SONDOTÉCNICA. Plano Estratégico de Recursos Hídricos da Bacia Hidrográfica dos rios Guandu, da Guarda e Guandu Mirim (Contrato 31/ANA/2005). Rio de Janeiro: Sondotécnica/Comitê Guandu/ANA, 2005.

SUGUIO, K. Geologia do Quaternário e mudanças ambientais: (passado+presente $=$ futuro?). São Paulo: São Paulo's Comunicação e Artes Gráficas, 1999.

ZUQUETTE, L.V. \& GANDOLFI,N. Cartografia Geotécnica. São Paulo: Oficina de Texto, 2004.

Recebido em 16/03/2010 Aceito em 30/10/2010

Notas

1Superfície de erosão ou de aplainamento é uma superfície do terreno com altitudes semelhantes e mais ou menos contínua, formada ao mesmo tempo por processos erosivos ou deposicionais (fluviais, glaciais e de encosta) atuantes na porção externa da Terra (Suguio, 1999). No SE brasileiro, Bigarella et al. (1975 apud Suguio, 1999) reconheceram três níveis de pediplano Pd1, Pd2 e Pd3 - correspondentes a uma superfície nivelada em valores altimétricos semelhantes e que foi formada pelo recuo paralelo das encostas, num processo característico de fases semiáridas ocorridas no passado, nesta região.

2 Os agregados para construção civil são materiais granulares, definidos de acordo com sua granulometria em: areia (partículas com diâmetros entre 0,06 mm e $2 \mathrm{~mm}$ ) e cascalho (partículas com diâmetros entre $2 \mathrm{~mm}$ e $64 \mathrm{~mm}$ ). 